\title{
Impact Testing of Stainless Steel Material at Cold Temperatures
}

\author{
PVP 2008
}

Dana K. Morton

Robert K. Blandford

Spencer D. Snow

\author{
July 2008
}

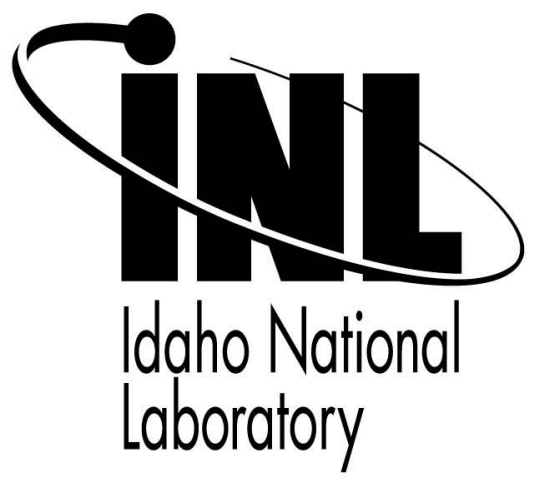

This is a preprint of a paper intended for publication in a journal or proceedings. Since changes may be made before publication, this preprint should not be cited or reproduced without permission of the author. This document was prepared as an account of work sponsored by an agency of the United States Government. Neither the United States Government nor any agency thereof, or any of their employees, makes any warranty, expressed or implied, or assumes any legal liability or responsibility for any third party's use, or the results of such use, of any information, apparatus, product or process disclosed in this report, or represents that its use by such third party would not infringe privately owned rights. The views expressed in this paper are not necessarily those of the United States Government or the sponsoring agency. 
PVP2008-61215

\title{
IMPACT TESTING OF STAINLESS STEEL MATERIAL AT COLD TEMPERATURES ${ }^{1}$
}

\author{
Dana K. Morton \\ Robert K. Blandford and Spencer D. Snow \\ Idaho National Laboratory \\ P.O. Box 1625 \\ Idaho Falls, Idaho 83415-3760 \\ United States of America
}

(208) 526-1274, (208) 526-4311, Dana.Morton@inl.gov

\begin{abstract}
Stainless steels are used for the construction of numerous spent nuclear fuel or radioactive material containers that may be subjected to high strains and moderate strain rates during accidental drop events. Mechanical characteristics of these base materials and their welds under dynamic loads in the strain rate range of concern are not well documented. However, a previous paper [1] reported on impact testing and analysis results performed at the Idaho National Laboratory using 304/304L and 316/316 L stainless steel base material specimens at room and elevated temperatures.

The goal of the work presented herein is to add recently completed impact tensile testing results at $-20^{\circ} \mathrm{F}$ conditions for dual-marked 304/304L and 316/316L stainless steel material specimens (hereafter referred to as $304 \mathrm{~L}$ and $316 \mathrm{~L}$, respectively). Recently completed welded material impact testing at $-20^{\circ} \mathrm{F}$, room, $300^{\circ} \mathrm{F}$, and $600^{\circ} \mathrm{F}$ is also reported. Utilizing a drop-weight impact test machine and 1/4-inch to 1/2-inch thick dog-bone shaped test specimens, the impact tests achieved strain rates in the 4 to 40 per second range, depending upon the material temperature. Elevated true stress-strain curves for these materials reflecting varying strain rates and temperatures are presented herein.
\end{abstract}

\section{INTRODUCTION}

The Department of Energy's (DOE) National Spent Nuclear Fuel Program (NSNFP), working with the Office of Civilian Radioactive Waste Management (OCRWM), the Idaho National Laboratory (INL), and other DOE sites, has supported the development of canisters for loading and interim storage, transportation, and disposal of DOE spent nuclear fuel (SNF). These canisters must be capable of performing a variety of functions during all three of these designated uses. Handling and transport operations require that the canister design have a high degree of confidence against failure of the containment boundary if the canister is subjected to loads (e.g., accidental drop events) resulting in large plastic deformations and high strains, strains which would likely occur over a range of moderate strain rates ( 1 to 200 per second).

The first phase of material impact testing stainless steel base and welded materials (at $-20^{\circ} \mathrm{F}$, room, $300^{\circ} \mathrm{F}$, and $600^{\circ} \mathrm{F}$ temperatures reflecting strain rates below 40 per second) is now complete. Higher strain rates of interest (40 to 200 per second) at the same temperature conditions still need to be investigated. Both base and welded materials must be investigated, ideally using the same material heats previously strain rate tested so that meaningful comparative insights can be established.

To assess the containment integrity of these SNF canisters under dynamic impact loading, the preferred approach is to use nonlinear plastic analytical methods with limited or no confirmatory testing. Improved software and methodologies for performing inelastic, large deformation analyses are now common and offer numerous advantages relative to full-scale component testing, including relatively low cost analytical simulations, ease of evaluating material and design options, elimination of costs associated with actual test component fabrication, testing, post-test disposal, etc. In order to rely only on an analytical approach, accurate results from methodologies

\footnotetext{
${ }^{1}$ Work supported by the U. S. Department of Energy, Office of Environmental Management (National Spent Nuclear Fuel Program at the Idaho National Laboratory) under DOE Idaho Operations Office Contract No. DE-AC07-05ID14517.
} 
and software must be demonstrated which in turn mandate a precise definition of inelastic, dynamic material properties (e.g. true stress-strain curves reflecting strain rate effects).

Variables such as temperature, welded material, aged material properties, and project specific conditions (if appropriate) must also be considered.

The INL developed a drop-weight impact testing machine (ITM) to begin the consideration of these variables and determine strain rate elevated true stress-strain curves for stainless steel materials. A high-speed digital camera was used to record the deformation time history of the impact event. The slope of the initial strain versus time curve yields the strain rate, as indicated in Figure 1 below. Previous ASME PVP Conference papers [2 and 3] described the ITM and the basic testing methodology employed.

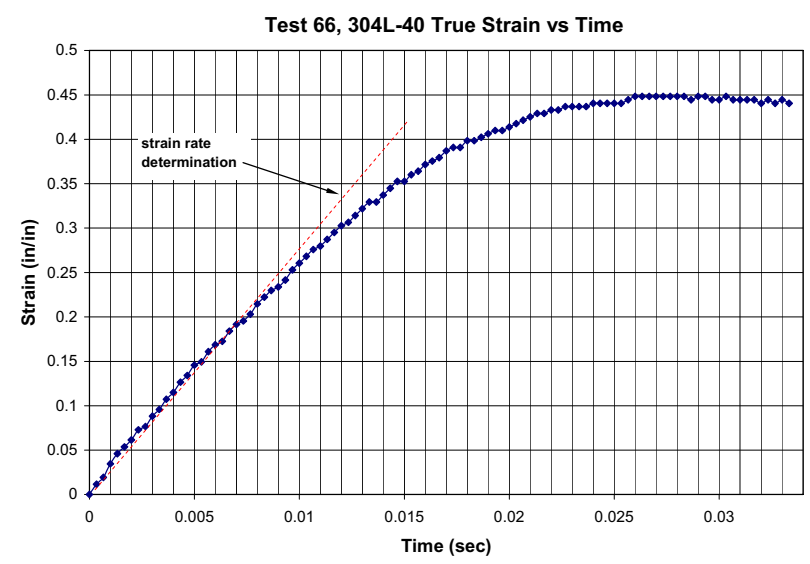

Figure 1. Strain Rate Determined Using High Speed Camera Data

A "total impact energy method" was developed for impact tensile testing using the concept that the area under a true stress-strain curve (up to the uniform strain limit - the strain at the onset of necking) is equivalent to the amount of energy (strain energy) that the test specimen gauge length volume of material can absorb up to a specific strain level achieved. The total impact energy method develops a strain rate elevated true stress-strain curve by multiplying each stress point on the quasi-static curve by a constant (referred to as the 'factor value'). The constant is the ratio of the impact energy imparted to the test specimen divided by the area under the quasi-static true stress-strain curve up to the true strain achieved in the impact test specimen. Elevated true stress-strain curves (reflecting strain rate effects) produced using this methodology are considered valid up to the uniform strain limit of the material. Future testing and analysis efforts may better define the curve between the uniform strain limit and failure.

\section{TEST SPECIMEN GEOMETRIES}

Figure 2 illustrates the typical test specimen geometries used for material impact testing. Generally speaking, test specimens made from $1 / 4$-inch thick material (identified herein as A22 or D22 geometries) were used for strain rates below 16 per second and $1 / 2$-inch thick test specimens (identified herein as A or D44 geometries) were used for strain rates greater than 16 per second. Test specimens used for $-20{ }^{\circ} \mathrm{F}$ and elevated temperatures had gauge lengths equal to 3 inches (D22 and D44 test specimen geometries). Room temperature impact testing used test specimens with gauge lengths of 3 and 4-1/2 inches (A22 and A test specimen geometries). Square crosssection profiles were used for all impact test specimens. The $1 / 4$-inch and $1 / 2$-inch materials were from different material heats. Welded test specimens were cut from plate welded together using a gas tungsten arc welding process. The welded material traversed the entire center length of the test specimen, including the gauge length. These welded specimens needed additional machining to remove the weld crown and establish a square cross-section along the test specimen gauge length.

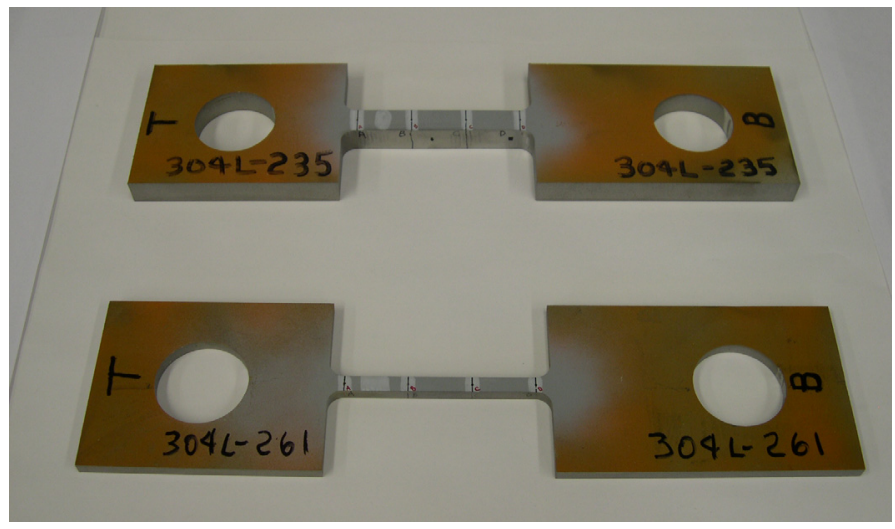

Figure 2. Test Specimens Used For Material Impact Testing

\section{IMPACT TESTING AT ROOM AND ELEVATED TEMPERATURES}

Reference 1 discussed the procedure used to perform the impact tensile testing of base material at room, $300{ }^{\circ} \mathrm{F}$, and $600{ }^{\circ} \mathrm{F}$ temperatures. The procedure for testing the welded material at these same temperatures was identical. Hence, the same temperature tolerances discussed in Reference 1 would also be applicable to the welded material impact tests.

\section{IMPACT TESTING AT COLD TEMPERATURE}

The Code of Federal Regulations regarding the transportation of radioactive material (10 CFR Part 71.73 [4)]) identifies a variety of hypothetical accident conditions that need to be evaluated and the worst case lower temperature to be considered for these events is $-20^{\circ} \mathrm{F}$. Therefore, the goal of this research was to impact test at that cold temperature. The cold temperatures were achieved by placing the test specimens in a research freezer that could maintain temperatures down to approximately $-40{ }^{\circ} \mathrm{F}$.

Prior to impact testing, temperature baseline testing was performed to establish the acceptable overnight soak temperature range and the time duration needed to wait (after removal from the freezer to achieve the $-20{ }^{\circ} \mathrm{F}$ target temperature) before the impact test could occur. Since the entire test specimen was soaked overnight (a minimum of 16 
hours prior to impact) to a uniform cold temperature, temperature gradients along the test gauge length were not anticipated to be significant. Hence, the baseline temperature testing was completed with three thermocouples (each embedded to half of the specimen width) attached at the center and the two end locations of the gauge length. It was necessary to consider the time needed to remove the test specimen from the freezer, load the specimen into the test fixture and prepare for the impact test. This time span typically took about 30 seconds. Therefore, the test specimen needed to be "overchilled" to a starting temperature in the range of -32 to $-34^{\circ} \mathrm{F}$ so that this preparation time interval could be incorporated into the test procedure. Tabs of masking tape placed on the test specimen prior to the overnight cooldown gave test personnel a way to handle each test specimen without directly touching (and locally warming) the test specimen. Since the baseline temperature results were extremely close in value to each other and that the "warming up" rate was also very repeatable, direct test specimen temperature measurements prior to impact testing were not considered necessary nor was there any time to perform these measurements. Performing this cold temperature testing by cooling only the test specimen avoided cooling the entire tensile test fixture made of A36 carbon steel, eliminating structural concerns over repetitive impact loads.

Table 1 indicates the time interval for removal from the freezer to release of the drop weight and the worst-case temperature tolerances achieved during the numerous baseline temperature tests completed. These temperature ranges are at the time of impact. The weighted average temperature covers the entire test specimen gauge length (weighted average of all three thermocouples) whereas the $\max / \mathrm{min}$ temperature ranges are the highest or lowest of the three thermocouple temperatures regardless of location. The weighted average temperatures and maximum and minimum temperatures were very close to the target test temperature of $-20^{\circ} \mathrm{F}$. The weighted averages were actually slightly colder than $-20^{\circ} \mathrm{F}$ (ranging from -20.7 to $-23.6^{\circ} \mathrm{F}$ ) and the warmest single temperature achieved was $-19^{\circ} \mathrm{F}$ with the coldest being $-24.3{ }^{\circ} \mathrm{F}$.

Table 1. Release Times and Temperature Tolerances

\begin{tabular}{|c|c|c|c|c|}
\hline $\begin{array}{c}\text { Target } \\
\text { Temp. } \\
\left({ }^{\circ} \mathrm{F}\right)\end{array}$ & $\begin{array}{c}\text { Test } \\
\text { Specimen } \\
\text { Thickness } \\
\text { (in.) }\end{array}$ & $\begin{array}{c}\text { Drop } \\
\text { Weight } \\
\text { Release } \\
\text { Time }(\mathrm{sec})\end{array}$ & $\begin{array}{c}\text { Weighted } \\
\text { Avg. } \\
\text { Temp. } \\
\text { Range }\left({ }^{\circ} \mathrm{F}\right)\end{array}$ & $\begin{array}{c}\text { Max/Min } \\
\text { Temp. } \\
\text { Range } \\
\left({ }^{\circ} \mathrm{F}\right)\end{array}$ \\
\hline \multirow{2}{*}{-20} & $1 / 4$ & 36 & $-1.8 /-3.6$ & $+1.0 /-4.3$ \\
\cline { 2 - 5 } & $1 / 2$ & 51 & $-0.7 /-2.1$ & $-0.5 /-2.3$ \\
\hline
\end{tabular}

\section{IMPACT TENSILE TEST RESULTS}

Both 304L and 316L base and welded material test specimens at $-20{ }^{\circ} \mathrm{F}$ and welded specimens at room and elevated temperatures were subjected to dynamic impact loads in order to achieve strain rates in the 4 to 40 per second range, depending upon temperature. Higher strain rates at the lower temperatures were easier to achieve than at higher temperatures.
Before discussing the impact tensile test results, it is important to remember that there is variability in material properties, even within a single plate. As indicated in Reference 5, material properties including yield strength can typically vary by $7 \%$ and the tensile strength of welds can typically vary by $10 \%$. Similar variations were experienced during the impact testing, with the same material heat, drop weight, and drop height producing varying strain results in multiple test specimens. In light of this, the impact results were not expected to behave as a precise linear or quadratic function.

Quasi-static tensile test results provide the baseline for understanding how strain rate effects change a true stress-strain curve. Quasi-static tensile testing was performed following the requirements of ASTM A370 [6]. A 2007 PVP paper [7] contains additional information on the quasi-static testing performed to support this strain rate testing effort. Material impact testing, using the ITM, yielded the actual strain history response of the test specimen to a defined level of impact energy. Using the "total impact energy method" previously discussed, the amount of impact energy absorbed by the test specimen was compared to the amount of energy under the quasi-static true stress strain curve (up to the strain achieved in the test specimen) to determine the factors.

These factors, calculated for each impact test, are then plotted against the achieved strain rate for each material and temperature. The significance of these factor versus strain rate curves is that one is able to predict how much a strain rate curve will increase relative to the quasi-static stress-strain curve without having to perform testing at that specific strain rate. Previous PVP papers [2 and 3] took the approach of trying to develop a strain rate elevated true stress-strain curve at specific strain rates. This approach was based on using the average of at least three impact tests at the specified strain rate $(+/-2$ per second). With the factor versus strain rate curve approach, many tests (at least 20 impact tests) are used to establish a linear curve fit over the identified strain rate range and the curve fit is then used to calculate the factor needed to generate the strain rate elevated true stress-strain curves. These factor curves are presented with the acknowledgement that the full range of strain rate information has not yet been achieved so the presented curves are indeed limited to the range of strain rates indicated. The assumption of a linear variation was deemed acceptable at present but may very well change with additional data at higher strain rates.

During final report writing efforts, all data (including the room, $300^{\circ} \mathrm{F}$, and $600^{\circ} \mathrm{F}$ testing reported in Reference 1) was thoroughly reviewed. Minor corrections were made that ultimately resulted in small adjustments to the results previously reported. In addition, it was decided to add a single data point to each set of data for each temperature for each material. That single data point $(0,1)$ reflects a factor value equal to one at a strain rate value of essentially zero (reflecting the quasi-static tensile test results). Finally, since the welded specimens proved to behave very similar to the base material 
specimens in terms of strain rate response, the welded material results were combined with the base material results. The major difference between the base and welded material results were the uniform strain limits, with the welds having lower values.

Figures 3 through 6 illustrate the resulting factors for 304L material at $-20{ }^{\circ} \mathrm{F}$, room, $300{ }^{\circ} \mathrm{F}$, and $600^{\circ} \mathrm{F}$ temperatures respectively. Figures 7 through 10 illustrate the same information for $316 \mathrm{~L}$ material. These curves reflect multiple material heats. Note that the data point legend for each plot indicates the test specimen geometry (A, A22, D44, or D22), followed by a 3 or 4 digit heat number indicator, and whether the test was a base or welded material specimen (welded test specimens include a $\mathrm{W}$ in the callout and the data points are triangular shaped). Smaller data points represent $1 / 4$-inch thick specimens and larger data points indicate $1 / 2$-inch thick test specimens. Also evident in each plot is the added single data point of $(0,1)$ represented as a square. A linear curve fit was established for each factor versus strain rate curve and is shown on each plot. This curve fit was not forced to go through the $(0,1)$ point. Comparing the linear curve fits, one can see a fairly consistent pattern of the slopes (with one exception) increasing with increasing temperature and with the y-intercept decreasing as the temperature increases.

Using the linear curve fit information from the factor curve relationships, the strain rate elevated true stress-strain curves can be generated, allowing for further insights to be recognized. Since the factor versus strain rate curves for the room and elevated temperatures presented in Reference 1 changed so little, the revised strain rate elevated true stress strain curves for those temperatures will not be presented again. Figures 11 and 12 do illustrate the strain rate elevated true stress-strain curves at 0 (quasi-static results), 5, 10, and 22 per second strain rates at $-20^{\circ} \mathrm{F}$ for $304 \mathrm{~L}$ and $316 \mathrm{~L}$ respectively. These strain rates were achieved for all temperatures during impact testing.

Although this research effort has not yet completed investigating the entire strain rate range of interest, certain insights can be observed by evaluating the data currently available. The strain rate elevated true stress-strain curves (Figures 11 and 12 for specific heats 54M7 and 230468, respectively) reflecting $-20{ }^{\circ} \mathrm{F}$ conditions clearly illustrate that strain rate effects do indeed increase the true stress-strain curves as the strain rate increases. Comparing 304L versus 316L curves of Figures 11 and 12 (plotted up to the uniform strain limit), the increased capacity to absorb impact energy appears more significant in the 304L than in the $316 \mathrm{~L}$ material.

Figures 13 and 14 (also heat specific curves) illustrate how the elevated true stress-strain curves at a strain rate of 22 per second vary with temperature. These two figures both indicate that at the same strain rate, increasing temperature decreases the strain rate gain in strength. Another observation from Figures 11 through 14 is the striking difference between the shape of the true stress-strain curve at $-20{ }^{\circ} \mathrm{F}$ and at the other temperatures. These curve shapes resulted during the quasi-static tensile testing performed [7]. Both the 304L and the $316 \mathrm{~L}$ showed this unique curve shape (as did the other repetitive tests at this cold temperature). Compared to the room temperature curves, there is clearly more energy absorption capacity at $-20{ }^{\circ} \mathrm{F}$ but the uniform strain limit is reduced.

More subtle effects can be characterized by looking at the actual factors shown in Table 2. In contrast to the result insights stated in the Reference 1 paper, the $316 \mathrm{~L}$ material no longer appears to have a significant decreasing rate of impact energy absorption capacity as the strain rate increases. The 304L material does typically have higher factors than the $316 \mathrm{~L}$ material at corresponding strain rates and temperatures. Finally, as previously indicated with the observations of Figures 13 and 14, the strain rate factor decreases with increasing temperature.

Additional insights gained from impact testing was that the uniform strain limit does not appear to vary with strain rate, at least up to the strain rates achieved with this testing.

Table 2. Factors For Specified Strain rates

\begin{tabular}{|c|c|c|c|c|}
\hline $\begin{array}{c}\text { Strain } \\
\text { rate } \\
\text { per sec }\end{array}$ & $\begin{array}{c}-20 \\
{ }^{\circ} \mathrm{F}\end{array}$ & $\begin{array}{c}\text { Room } \\
\text { Temp. }\end{array}$ & $\begin{array}{c}300 \\
{ }^{\circ} \mathrm{F}\end{array}$ & $\begin{array}{c}600 \\
{ }^{\circ} \mathrm{F}\end{array}$ \\
\hline \multicolumn{5}{|c|}{304 L Stainless Steel } \\
\hline 5 & 1.333 & 1.235 & 1.166 & 1.043 \\
\hline 10 & 1.361 & 1.278 & 1.210 & 1.094 \\
\hline 22 & 1.428 & 1.381 & 1.316 & 1.217 \\
\hline \multicolumn{5}{|c|}{316 L Stainless Steel } \\
\hline 5 & 1.275 & 1.265 & 1.162 & 1.040 \\
\hline 10 & 1.296 & 1.281 & 1.187 & 1.070 \\
\hline 22 & 1.346 & 1.321 & 1.247 & 1.140 \\
\hline
\end{tabular}

Forty finite element analyses were performed of various impact tests using the plastic analysis software ABAQUS/Explicit [8]. Material properties were input as either non-factored or factored true stress-strain curves. Table 3 provides percentage comparisons of both analysis prediction methods (using non-factored and factored data) to the resulting actual test gauge length deformations for the temperatures considered at two target strain rates, 10 per second and 22 per second. The plus values indicate over prediction and the negative values indicate under prediction. The Table 3 results clearly indicate that the strain rate adjusted (factored) input yields more accurate analysis predictions than when just the quasi-static (non-factored) true stress-strain curves are used. As expected, all of the analysis results using the non-factored input over predicted the axial deformation while the factored analyses had estimates above and below the actual deformation. 


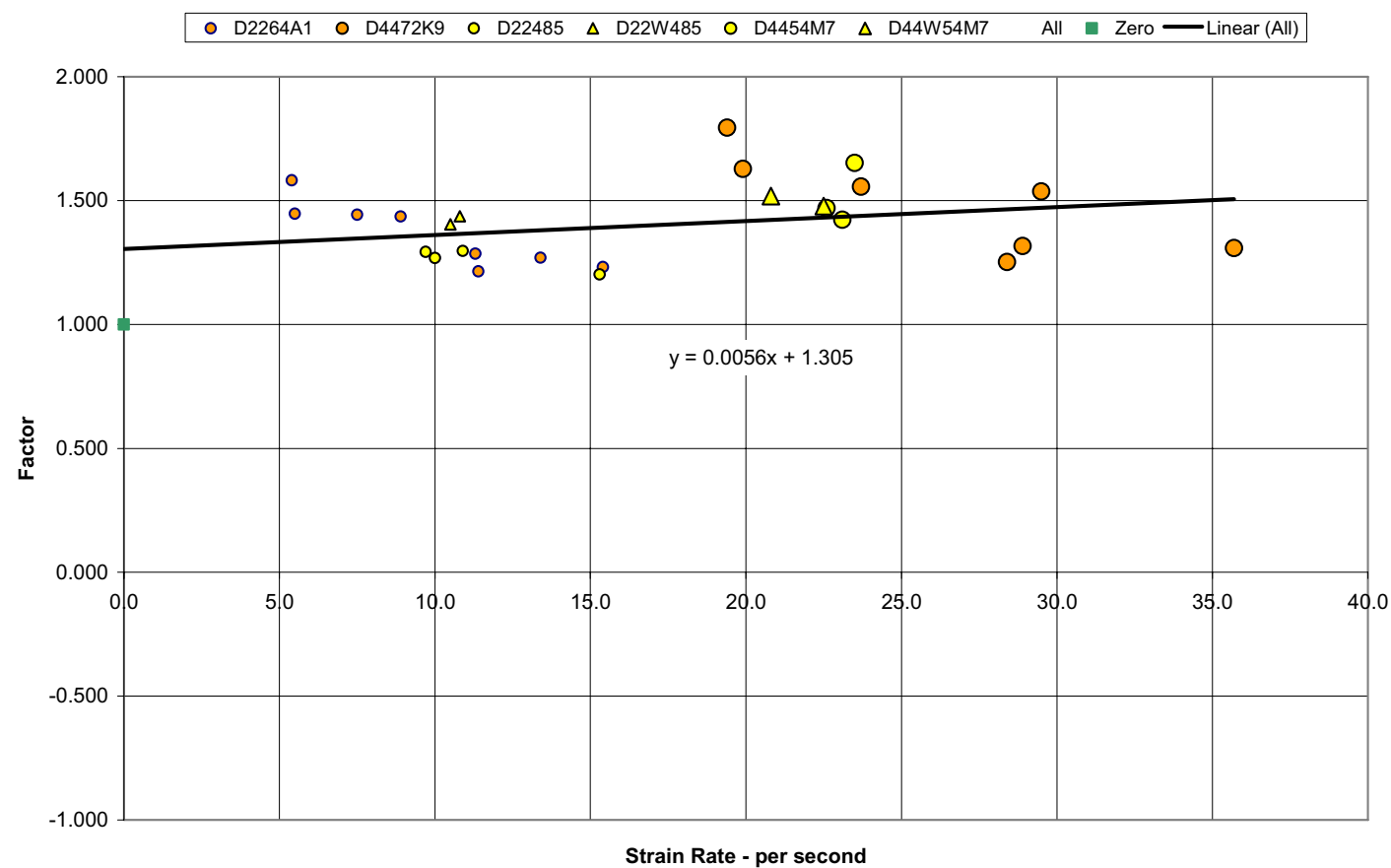

Figure 3. Factor Versus Strain Rate at -20F Temperature for 304L

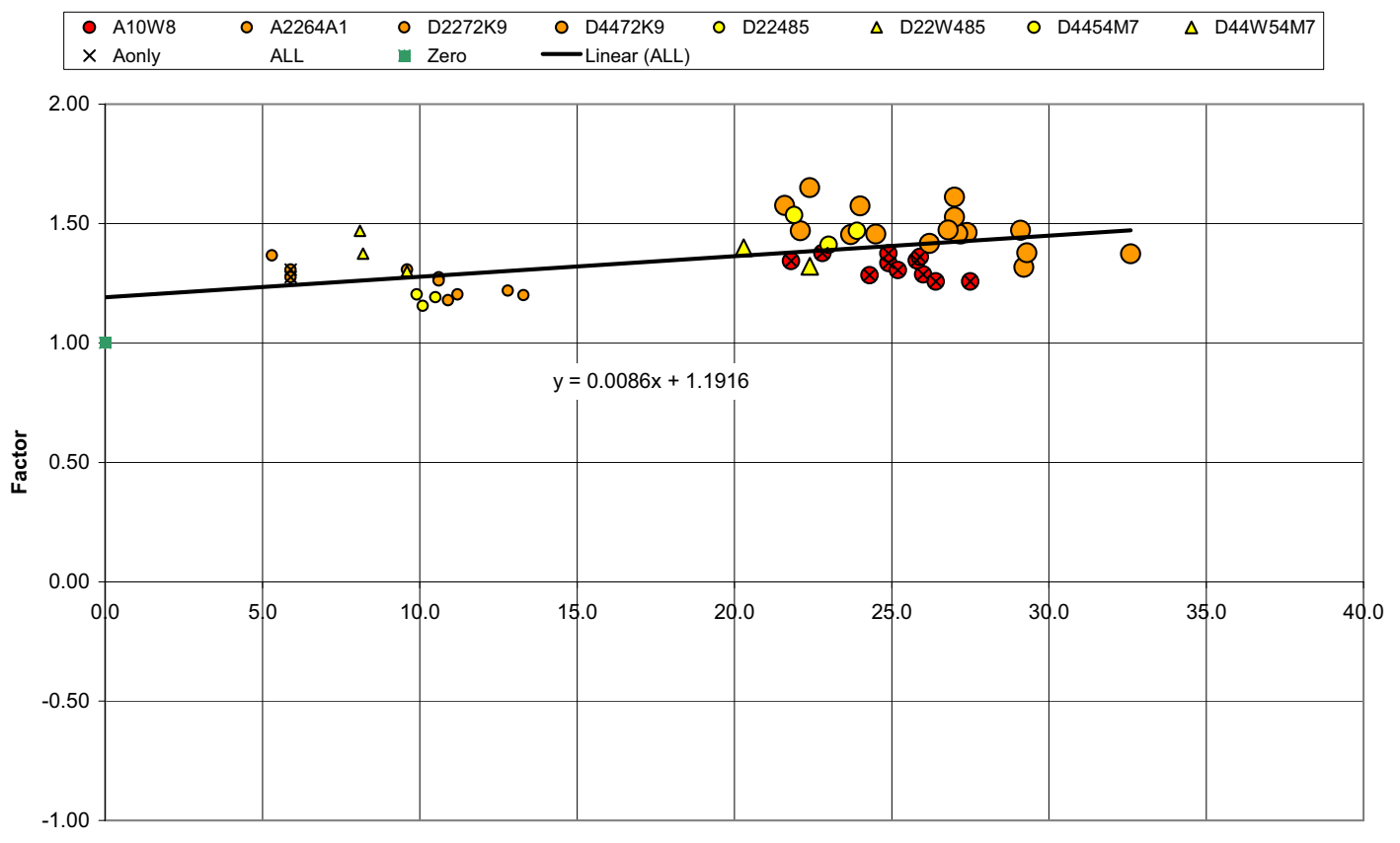

Strain Rate - per second

Figure 4. Factor Versus Strain Rate at Room Temperature for 304L 


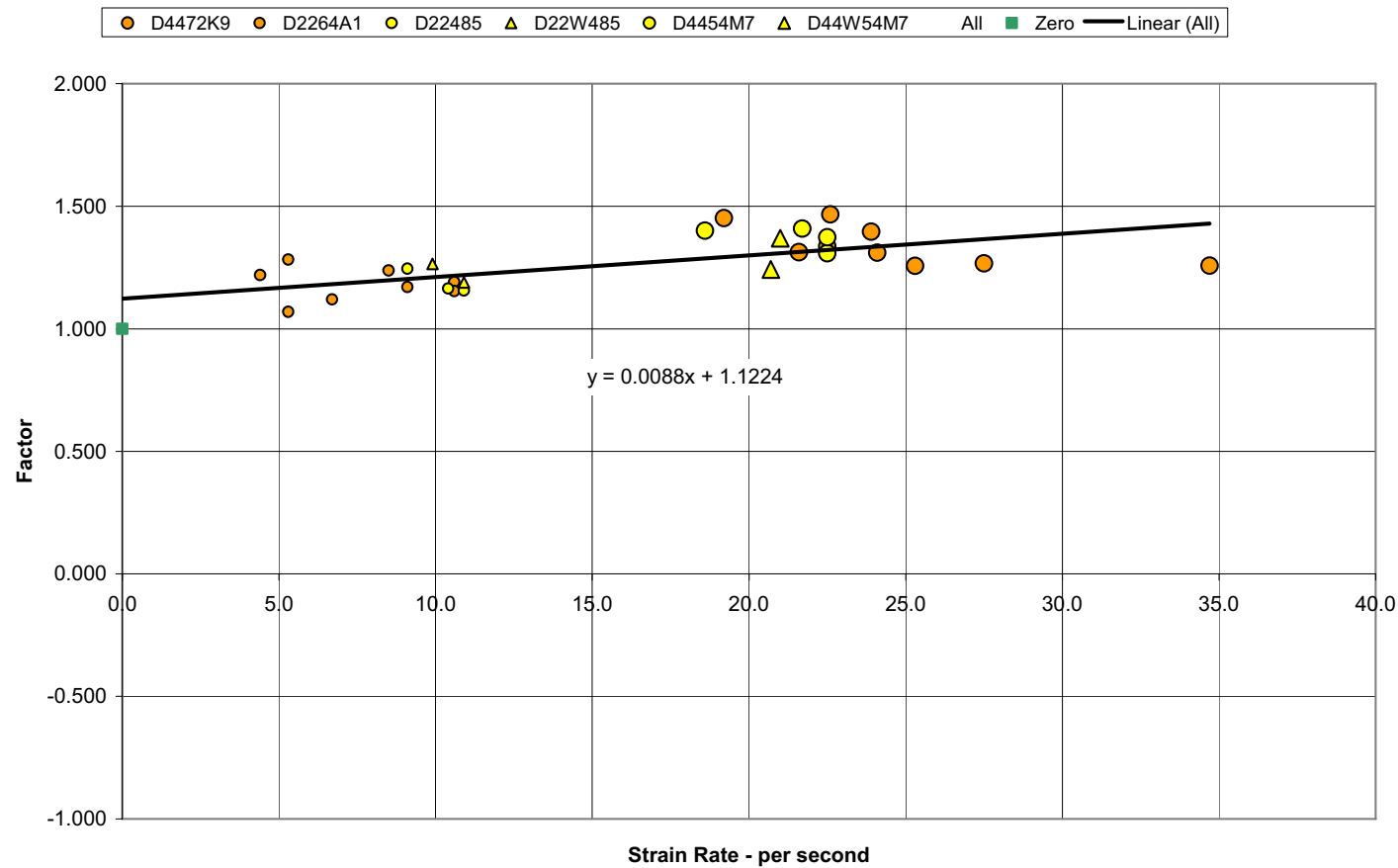

Figure 5. Factor Versus Strain Rate at 300F Temperature for 304L

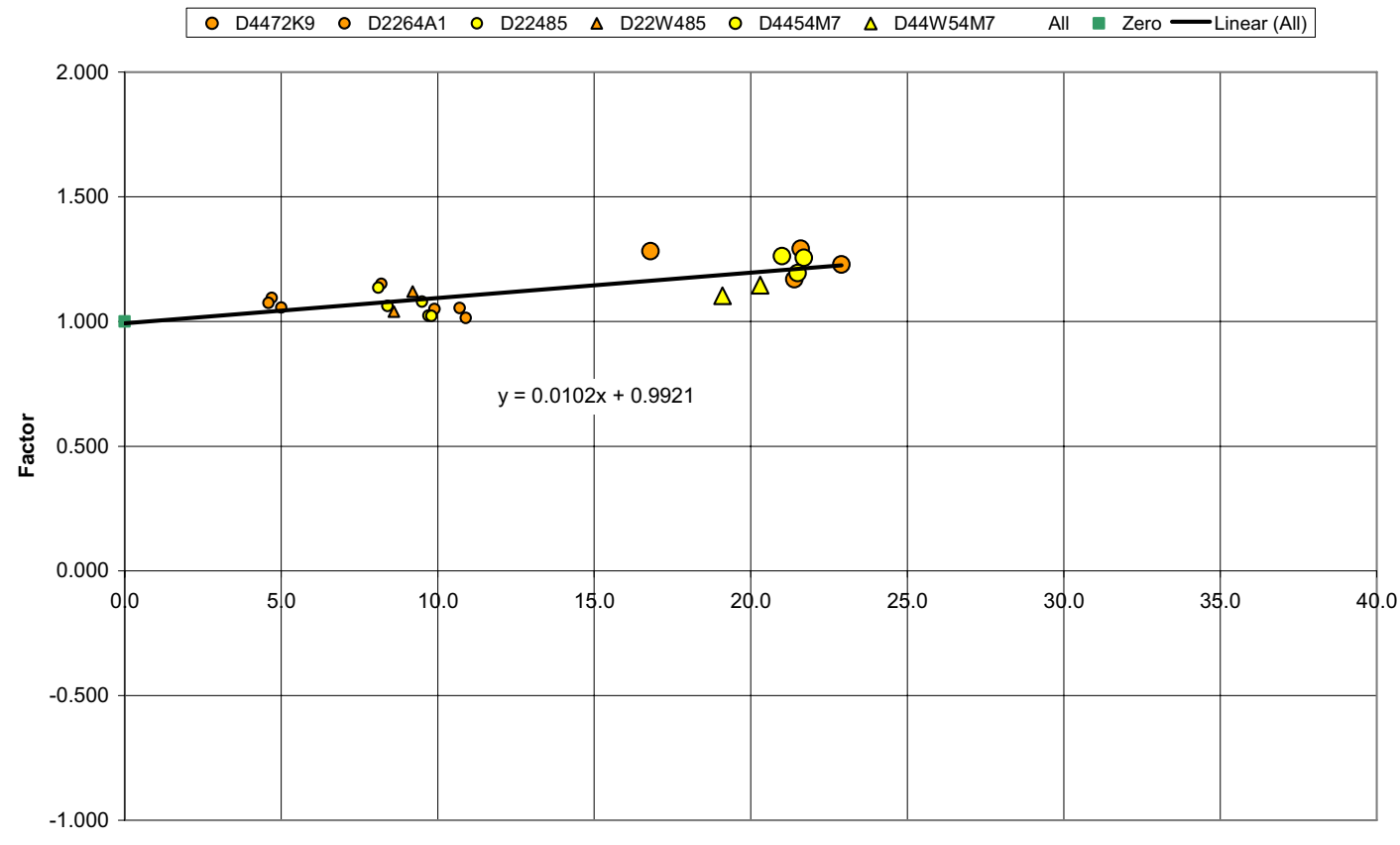

Strain Rate - per second

Figure 6. Factor Versus Strain Rate at 600F Temperature for 304L 


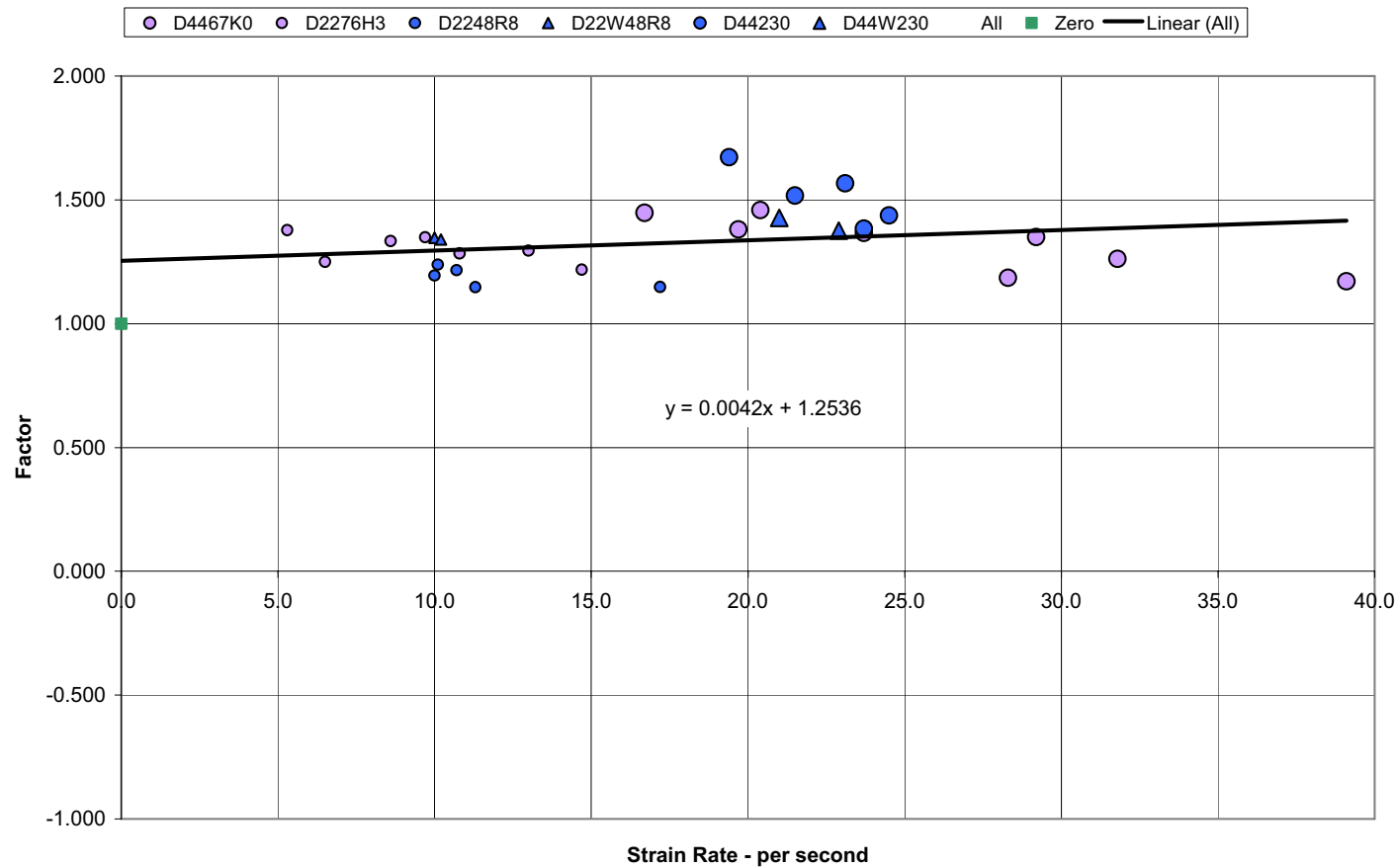

Figure 7. Factor Versus Strain Rate at -20F Temperature for $316 \mathrm{~L}$

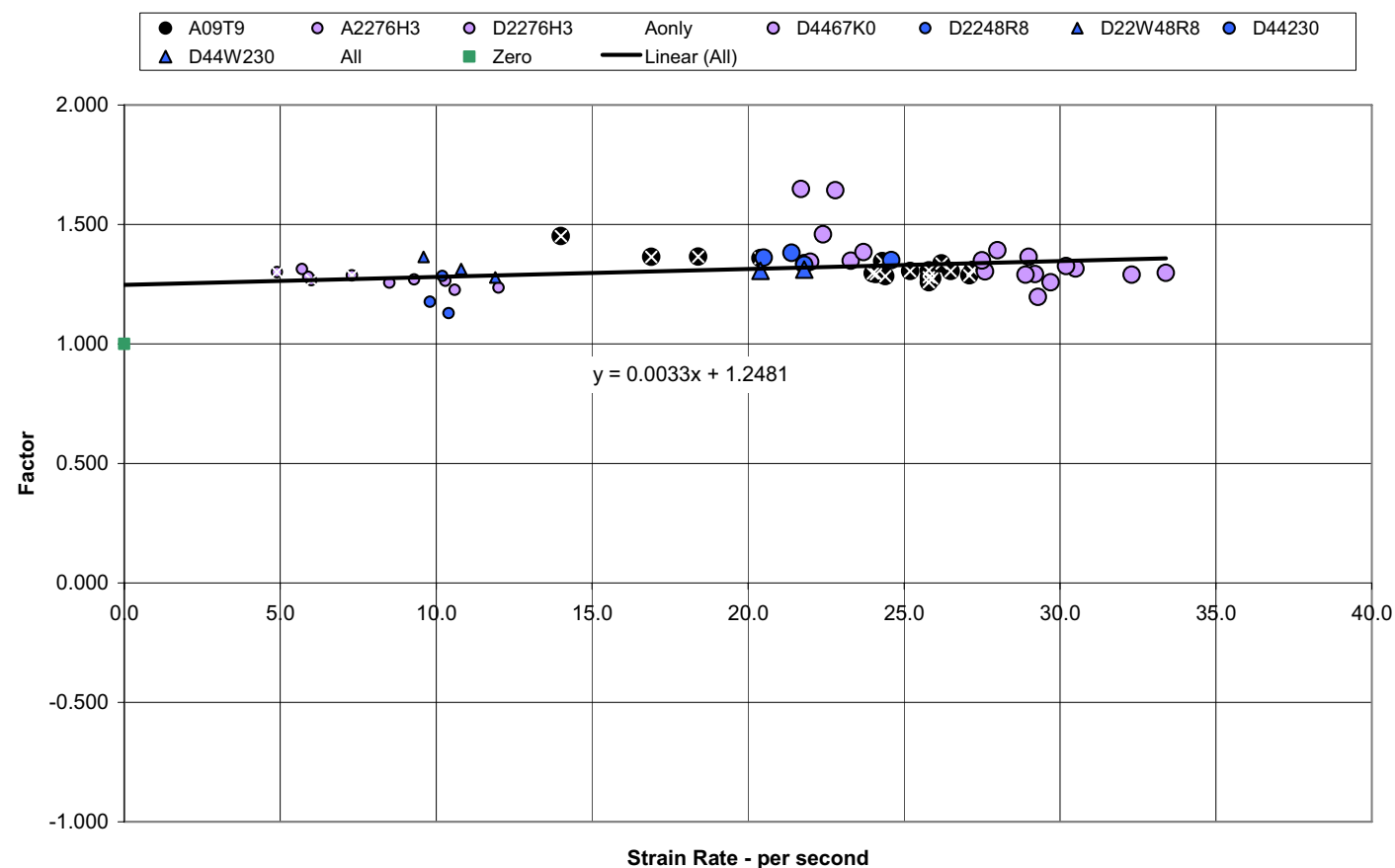

Figure 8. Factor Versus Strain Rate at Room Temperature for 316L 


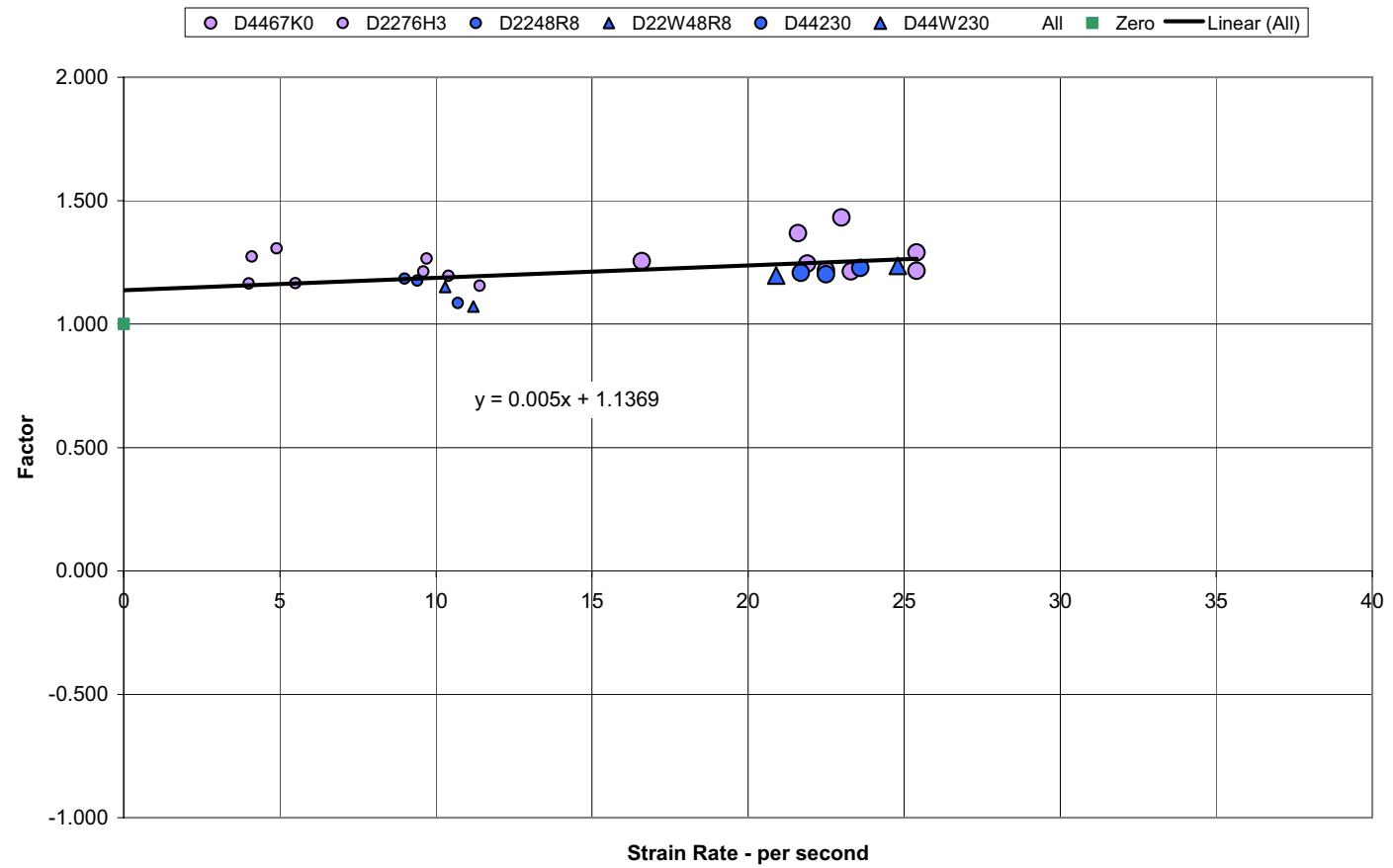

Figure 9. Factor Versus Strain Rate at 300F Temperature for 316L

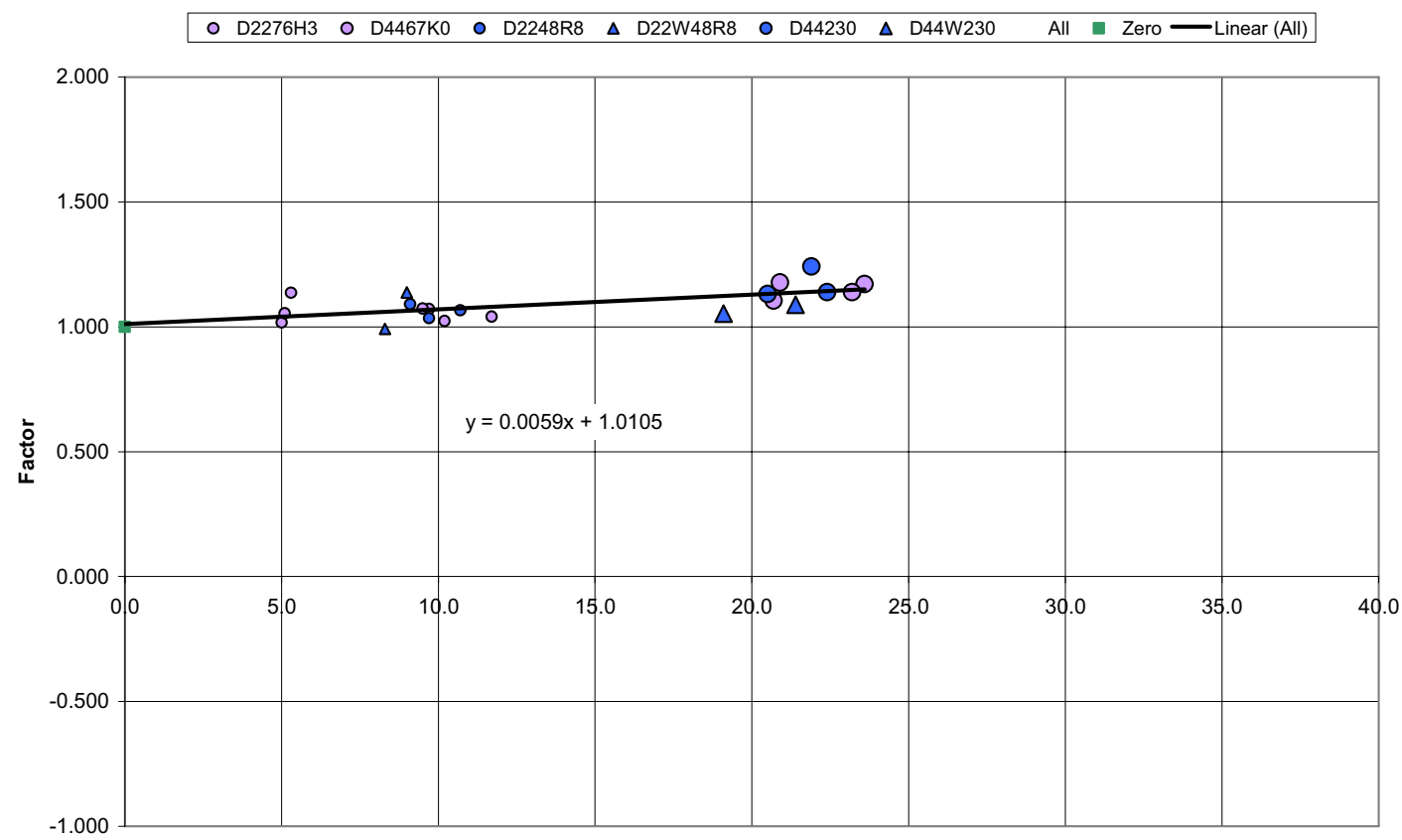

Strain Rate - per second

Figure 10. Factor Versus Strain Rate at 600F Temperature for 316L 


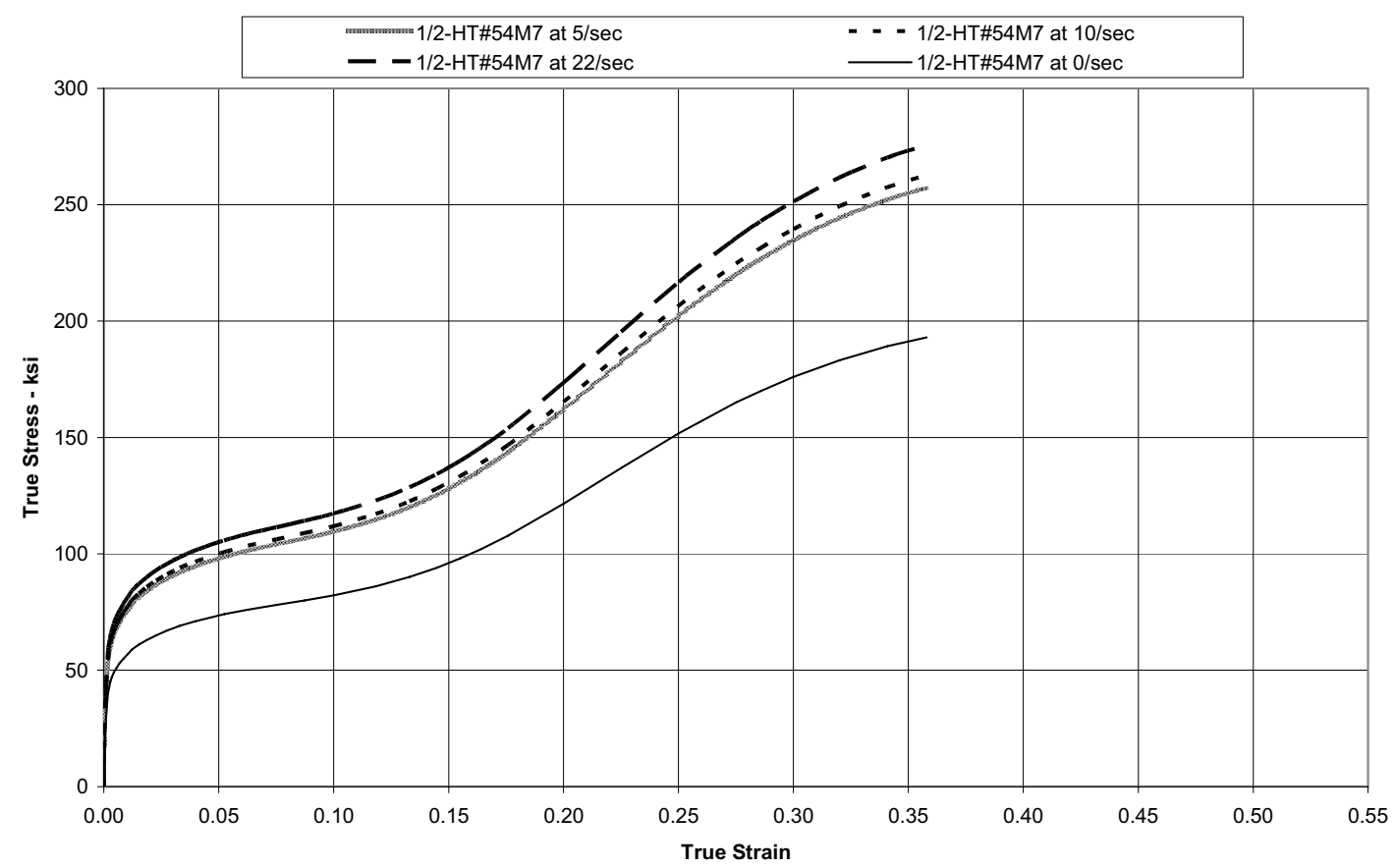

Figure 11. 304L True Stress-Strain Curve at $-\mathbf{2 0}^{\circ} \mathrm{F}$ Temperature with Varying Strain Rates

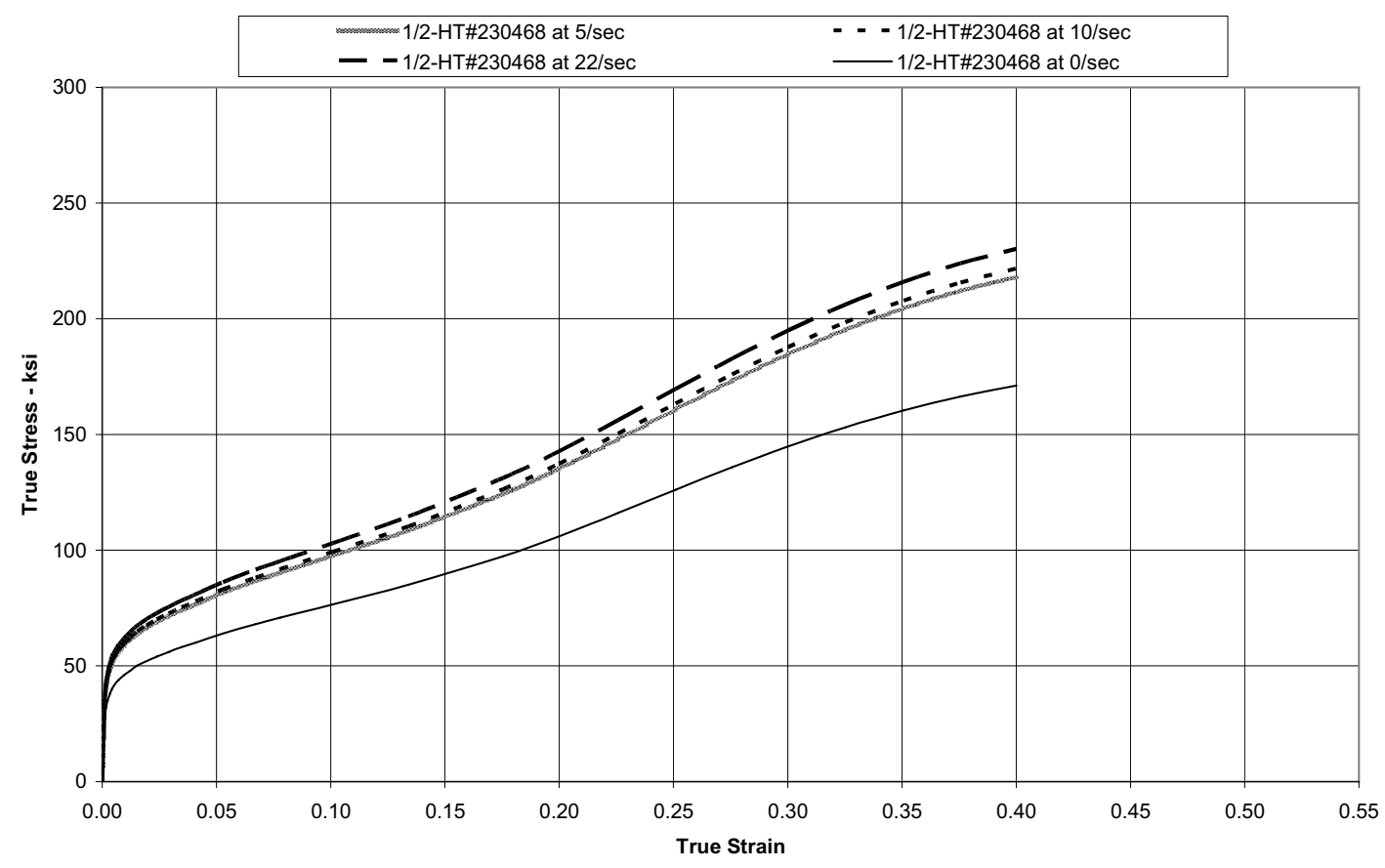

Figure 12. 316L True Stress-Strain Curve at $-\mathbf{2 0}^{\circ} \mathrm{F}$ Temperature with Varying Strain Rates 


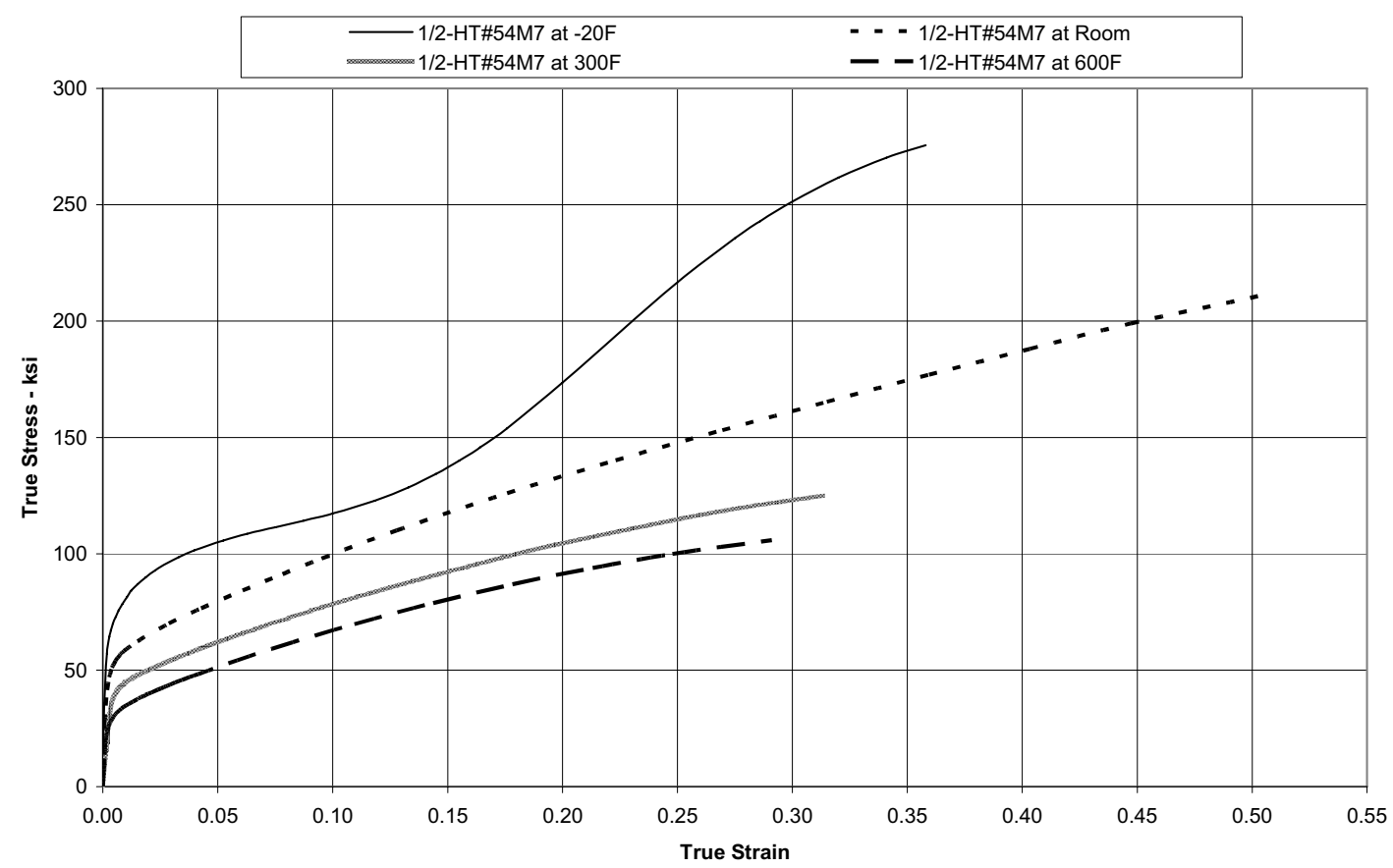

Figure 13. Variation of 304L True Stress-Strain Curve With Temperature at 22 Per Second Strain Rate

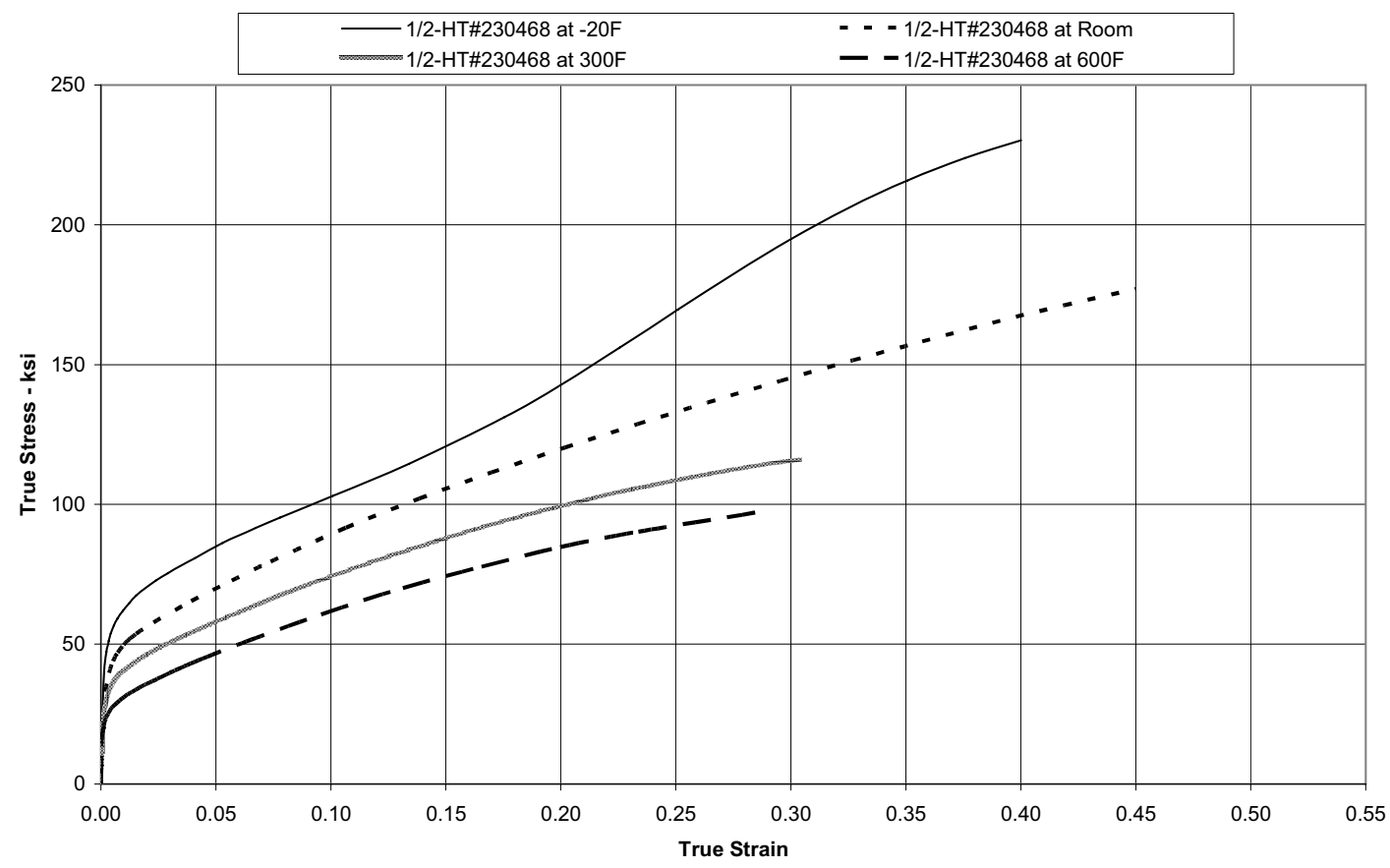

Figure 14. Variation of 316L True Stress-Strain Curve With Temperature at 22 Per Second Strain Rate 
In general terms, the analysis results show significant improvement for all temperatures except for the $600{ }^{\circ} \mathrm{F}$ results. The percentage variation at $600{ }^{\circ} \mathrm{F}$ between non-factored and factored input is reduced due to the lower strain rate factors, especially at the strain rates of 5 and 10 per second. These associated factors are less than 1.10, clearly within the variability of plate material properties.

The 2007 PVP paper [1] that discussed room and elevated temperature impact tensile testing also contained results of a smaller number of comparisons. Those ABAQUS/Explicit models used only one material input (304L or $316 \mathrm{~L}$ ) but comparisons were made to impact tests that reflected materials of different heats. Differences between the true stress-strain curves of various heats provided a significant portion of the predicted differences in gauge length deformations. This did not give the factors a fair representation of their true predictive capability. The numbers presented in the table below reflect an ABAQUS/Explicit model that contains the specific material heat of that test specimen under consideration at the temperature that the test was performed. In this way, the only significant variation in the comparison results from strain rate effects.

Table 3. Comparison of Using Factored Versus Non-Factored True Stress-Strain Input

\begin{tabular}{|c|c|c|c|c|}
\hline \multicolumn{4}{|c|}{ Percentage Analysis Accuracy of Axial Deformations } \\
\hline \multirow{2}{*}{ Temperature } & \multicolumn{2}{|c|}{ Non-Factored } & \multicolumn{2}{c|}{ Factored } \\
\cline { 2 - 5 } & $\mathrm{SR}=10$ & $\mathrm{SR}=22$ & $\mathrm{SR}=10$ & $\mathrm{SR}=22$ \\
\hline \multirow{2}{*}{$-20{ }^{\circ} \mathrm{F}$} & +24.8 to & +25.2 to & -6.2 to & -3.6 to \\
& +40.7 & +36.9 & +10.6 & +6.3 \\
\hline \multirow{2}{*}{ Room } & +22.6 to & +21.4 to & -5.5 to & -4.5 to \\
& +33.3 & +34.8 & +4.4 & +4.0 \\
\hline \multirow{2}{*}{$300^{\circ} \mathrm{F}$} & +11.4 to & +8.9 to & -7.8 to & -9.4 to \\
& +34.7 & +24.1 & +12.7 & -0.3 \\
\hline \multirow{2}{*}{$600^{\circ} \mathrm{F}$} & +2.6 to & +2.0 to & -5.7 to & -7.6 to \\
& +12.0 & +12.4 & +5.9 & -1.8 \\
\hline
\end{tabular}

\section{CONCLUSIONS}

The material impact testing reported herein has provided data to support the development of strain rate elevated true stress-strain curves for both 304L and 316L stainless steels that account for strain rate strengthening up to a strain rate of nearly 40 per second, depending upon temperature. The effects of strain rate decrease with increasing temperature. Base and welded materials appear to behave similarly during impact testing, but welded materials are not able to achieve strains as high as their associated base metal. The uniform strain limits for both welded material and base material do not appear to change from the values established during quasistatic tensile testing for the strain rate range discussed herein.

Using the strain rate data developed herein as material input in analytical models of the impact tensile tests performed resulted in analytical predictions that showed marked improvements when compared to material input reflecting quasi-static tensile test results. The strain rate elevated true stress-strain curves developed can be used in analytical simulations to more accurately predict the deformation and resulting material straining in spent nuclear fuel containers, canisters, and casks loaded by accidental drop events within the established strain rate range. Data produced in this test program may also be used in the development of strain-based acceptance criteria for application to SNF containers, canisters, and casks experiencing impact events.

\section{REFERENCES}

[1] Morton, D. K., Snow, S. D., Rahl, T. E., and Blandford, R. K., "Impact Testing of Stainless Steel Material at Room and Elevated Temperatures," American Society of Mechanical Engineers Pressure Vessels and Piping Conference, San Antonio, Texas, July 22-26, 2007, PVP2007-26182.

[2] Blandford, R. K., Morton, D. K., Rahl, T. E., and Snow, S. D., "Impact Testing of Stainless Steel Materials," American Society of Mechanical Engineers Pressure Vessels and Piping Conference, Denver, Colorado, July 17-21, 2005, PVP200571133.

[3] Snow, S. D., Morton, D. K., Rahl, T. E., Blandford, R. K., and Hill, T. J., "Preliminary Results of Stainless Steel Impact Bending Tests," American Society of Mechanical Engineers Pressure Vessels and Piping Conference, Vancouver, BC, Canada, July 23-27, 2006, PVP2006-ICPVT-11-93161.

[4] 10 CFR Part 71, "Packaging and Transportation of Radioactive Material”, Code of Federal Regulations, Office of the Federal Register, May 2005.

[5] Dowling, N. E., 1999, Mechanical Behavior of Materials, Upper Saddle River: Prentice Hall, Appendix B, p 803.

[6] ASTM A 370, "Standard Test Methods and Definitions for Mechanical Testing of Steel Products", ASTM International, effective date as of start of testing.

[7] Blandford, R. K., Morton, D. K., Snow, S. D., and Rahl, T. E., "Tensile Stress-Strain Results for 304L and 316L Stainless Steel Plate at Temperature," American Society of Mechanical Engineers Pressure Vessels and Piping Conference, San Antonio, Texas, July 22-26, 2007, PVP2007-26096. [8] ABAQUS/Explicit Version 6.6-3, ABAQUS, Inc., Providence, Rhode Island, 2006.

\section{NOTICE}

This paper was prepared as an account of work sponsored by an agency of the U. S. Government. Neither the U. S. Government nor any agency thereof, or any of their employees, makes any warranty, expressed or implied, or assumes any legal liability or responsibility for any third party's use, or the results of such use, of any information, apparatus, product or process disclosed in this report, or represents that its use by such third party would not infringe privately owned rights. The views expressed in this paper are not necessarily those of the U.S. DOE. This material is declared a work of the U.S. Government and is not subject to copyright protection in the United States. Approved for public release; distribution is unlimited. 